\title{
Assessment of soy phytoestrogens' effects on bone turnover indicators in menopausal women with osteopenia in Iran: a before and after clinical trial
}

\author{
Arezoo Haghighian Roudsari*1, Farideh Tahbaz , Arash Hossein-Nezhad², \\ Bahram Arjmandi ${ }^{3}$, Bagher Larijani ${ }^{2}$ and Seyed Masoud Kimiagar ${ }^{1}$
}

Address: ${ }^{1}$ School of Nutrition and Food Technology, Shaheed Beheshti University of Medical Sciences, Tehran, Iran, ${ }^{2}$ Endocrinology \& Metabolism Research center, Tehran university of Medical science, Tehran, Iran and ${ }^{3}$ Department of Nutritional Sciences, Oklahoma State University, Stillwater, OK, USA

Email: Arezoo Haghighian Roudsari* - ahaghighian@yahoo.com; Farideh Tahbaz - faridehta@yahoo.com; Arash HosseinNezhad - arash_hsi@yahoo.com; Bahram Arjmandi - arjmand@okstate.edu; Bagher Larijani - emrc@sina.tums.ac.ir; Seyed

Masoud Kimiagar - smkimiagar@yahoo.com

* Corresponding author

Published: 29 October 2005

Nutrition Journal 2005, 4:30 doi:10.1/86/1475-289|-4-30

This article is available from: http://www.nutritionj.com/content/4/I/30

(c) 2005 Roudsari et al; licensee BioMed Central Ltd.

This is an Open Access article distributed under the terms of the Creative Commons Attribution License (http://creativecommons.org/licenses/by/2.0), which permits unrestricted use, distribution, and reproduction in any medium, provided the original work is properly cited.

\begin{abstract}
Background: Osteoporosis is the gradual declining in bone mass with age, leading to increased bone fragility and fractures. Fractures in hip and spine are known to be the most important complication of the disease which leads in the annual mortality rate of $20 \%$ and serious morbidity rate of $50 \%$. Menopause is one of the most common risk factors of osteoporosis. After menopause, sex hormone deficiency is associated with increased remodeling rate and negative bone balance, leading to accelerated bone loss and micro-architectural defects, resulting into increased bone fragility.

Compounds with estrogen-like biological activity similar to "Isoflavones" present in plants especially soy, may reduce bone loss in postmenopausal women as they are similar in structure to estrogens.

This research, therefore, was carried out to study the effects of Iranian soy protein on biochemical indicators of bone metabolism in osteopenic menopausal women.

Materials and methods: This clinical trial of before-after type was carried out on 15 women 45-64 years of age. Subjects were given $35 \mathrm{~g}$ soy protein per day for 12 weeks. Blood and urine sampling, anthropometric measurement and 48-h-dietary recalls were carried out at zero, 6 and 12 weeks. Food consumption data were analyzed using Food Proccessor Software. For the study of bone metabolism indicators and changes in anthropometric data as well as dietary intake, and repeated analyses were employed.
\end{abstract}

Results: Comparison of weight, BMI, physical activity, energy intake and other intervening nutrients did not reveal any significant changes during different stages of the study. Soy protein consumption resulted in a significant reduction in the urinary deoxypyridinoline and increasing of total alkaline phosphatase $(p<0.05)$, although the alterations in osteocalcin, $c$-telopeptide, IGFBP3 and type I collagen telopeptide were not significant.

Conclusion: In view of beneficial effect of soy protein on bone metabolism indicators, inclusion of this relatively inexpensive food in the daily diet of menopausal women, will probably delay bone resorption, thereby preventing osteoporosis. 


\section{Backgrounds}

Menopause is a period normally occupying one-third of women's life [1]. Reduced bone density is one of the most prominent symptoms during menopause [2].

Osteoporosis is a serious problem for postmenopausal women which increases the risk of bone fracture and worsens with age, increasing from $4 \%$ in $50-59$ year age bracket to $50 \%$ in 80 years old women. Bone fractures are also prevalent in these women [3]. Today estrogen therapy (ERT) and drugs like bisphosphonates, calcitonin and raloxifene is employed to prevent and treat osteoporosis [4]. However, side effects such as breast cancer, endometrial adenocarcinoma [5] have limited the acceptance of these medications among women [6] and only 35\% to $40 \%$ of women ever start ERT, and many do not continue it [7].

Epidemiologic studies have shown osteoporotic fractures, cardiovascular disease, postmenopausal symptoms and some cancers to be less prevalent in Asians compared to their western counterparts. Hip fracture, for example, is 50-60\% less frequent among Asian compared to western women [8]. This advantage is gradually anihilated as Asian adapt western lifestyle [9]. These observations, prompted researchers to scrutinize Asian dietary habits. Soy is a part of Asian traditional diet [10], showing some relationship with the above-mentioned diseases [9].

Estrogen-like compounds such as isoflavones existing in plant foods specially soy $[11,12]$ can curb reduced bone density in menopausal women, due to their structural similarity [13]. Some studies have not, however, supported clearly the role of soy isoflavones in preventing osteoporosis [14].

Isoflavones are phyto-estrogens similar to women's estrogens and are bound to cellular estrogen receptors in various organs, thus phytoestrogens affinity is weak compared to human's estrogens. Recent studies have shown that cells have two types estrogen receptors $\alpha$ and $\beta$. Human estrogens have more affinity to $\alpha$-receptors, whereas, isoflavones have high affinity to $\beta$-receptors. $\beta$ receptors exist in brain, bone, bladder and vascular epithelium, being important in the function of non-steroid estrogens [15].

As soy cultivated in Iran is of different variety, namely "Gorgan" compared to other studies and because the Iranian food habits and food pattern is different [16] which might affect the metabolism of nutrients and isoflavones, this study was conducted to assess its effects compared to other countries. Furthermore there are still contradiction, in the literature regarding the role of soy isoflavones which justify implementation of this study.

\section{Methods}

This clinical trial of before and after type was carried out in 2003. Women referring to the osteoporosis clinic of Endocrinology \& Metabolism Research Centre of Tehran University of Medical Sciences for bone density measurement were screened to find osteopenic subjects and 15 postmenopausal 45-64 year old women were selected. Those women between 1 to 10 years postmenopause who were non-smokers and free from diseases entered this study.

Information on weight, height, body mass index, two 24$\mathrm{hr}$ food consumption recall and physical activity were collected at the start, 6 and 12 weeks of the study. Soy protein at $35 \mathrm{~g}$ level containing $98.3 \mathrm{mg}$ isoflavones were given to subjects daily. Subjects were provided with a special cup for measuring soy. Cooking instructions were also given to the subjects.

Blood and urine samplings were done in 3 stages, in the beginning and at the end of $6^{\text {th }}$ and $12^{\text {th }}$ week. Blood and urine samples were kept frozen until the end of the twelfth week at $-80^{\circ} \mathrm{C}$. Serum biochemical indicators were measured on the same day for all samples. Total alkaline phosphatase was assayed calorimetrically with Hitachi 902 autoanalyzer, osteocalcin by IRMA method using Biosource kit and Wizard gamacounter, IGFBP3 and c-telopeptide by ELISA using Biosources and Bioscience diagnostics respectively. Type I collagen telopeptide was determined by RIA method using Orion-Diagnostica on Wizard gama counter and urinary creatinine by colorimetrically method [17]. Food Processor software was used for food consumption survey and SPSS (version 11.5) was employed for statistical analysis of the data. All quantitative variables were then examined by Kolmogrof-Smirnof (KS) to ensure normality of distribution. To analyze any possible changes in food intake, intervening and biochemical variables in 3 stages, repeated measurement analysis was utilized. The purpose of this analysis was to ensure lack of significant changes of the variables. Significance level was set at below 5 percent $(\mathrm{P}<0.05)$.

\section{Results}

Subjects' anthropometric data are shown in Table 1. Mean age was $52.9 \pm 4.3$ years, years post menopause $5.47 \pm 3.4$ years and mean height $157.4 \pm 7.2$ centimeters. Mean body mass index and physical activity level remained unchanged. Mean food consumption figures were not different at 6 and 12 weeks compared to the start of the study (Table 2). Mean bone metabolic indicators for the 3 stages are given in Table 3 . After 12 weeks of soy consumption total serum alkaline phosphatase (TALP) significantly increased while urinary deoxypyridinoline (DPD) decreased $(P<0.05)$. Other indicators namely osteocalcin, insulin growth factor binding protein (IGFBP3), c-tel- 
Table I: Subjects anthropometric data in 3 stages of the study $(n=15)$.

\begin{tabular}{llll}
\hline Indicators & At the start & 6 weeks & 12 weeks \\
\hline Weight (kg) & $68 \pm 7.5^{*}$ & $68 \pm 7.6$ & $68 \pm 7.8$ \\
BMI (kg/m $\left.\mathbf{m}^{2}\right)$ & $27.4 \pm 3^{* *}$ & $27.4 \pm 3$ & $27.4 \pm 3$ \\
\hline
\end{tabular}

$*$ Mean \pm SD

** Mean height was $157.2 \pm 7.2$.

opeptide and type-I collagen telopeptides did not change significantly.

\section{Discussion}

The results demonstrated soy protein consumption to have caused increase in TALP and reduction in DPD in menopausal women with osteopenia, while other parameters were not significantly difference. Comprehensive human studies on the effect of soy on TALP have not been carried out. In Arjmandi et al studies on rats a slight but insignificant increase in TALP was seen [18-20]. The crucial role of gut microflora in the metabolism of isoflavones in human beings has also been previously explored [21]. In vivo studies proved that bacteria in the gastrointestinal tract play an important role in determining the magnitude and pattern of isoflavone bioavailability [22]. However, only 30 to $40 \%$ of the population can produce equol from daidzein and interindividual differences in the bacteria responsible for equol production $[23,24]$. Register et al observed a significant fall in TALP in monkeys after 12 weeks [25]. Animal models such as monkey may convert daidzein into equol more readily than 30 to $50 \%$ of humans. It has been shown that equol possesses more estrogen-like properties than daidzein. This is why isoflavone efficacy has been less pronounced in monkeys and the results have been reported as reduced TALP levels $[26,27]$.

TALP is an insensitive marker for bone formation compared to bone-specific alkaline phosphatase (BAP) or osteocalcin (OC). In this study, serum osteocalcin as a sensitive marker for bone formation has not changed during interventional period, indicating that soy protein may not enhance bone formation.
With regard to bone resorption, our results showed reduced urinary DPD levels following soy consumption which agrees with the finding of other investigators [2830]. The effect of isoflavones on this indicator is so strong that Uesagi et al [31] observed consuming $61.8 \mathrm{mg}$ of isoflavone for 4 weeks results in a significant reduction in urinary DPD. It can be said that DPD acts as a bridge between collagen fibrils which enter urine with collagen breakdown. As this is a very specific marker for bone resorption, its significant reduction in our study suggests soy consumption may prevent degradation of collagen the major protein in bone matrix [17].

Other serum indicators of bone metabolism were not affected in our study. In most studies on the effects of isoflavones in rats these phytochemicals, have been reported to have caused rises [32], no change $[19,20]$ and even reduction [14] in bone formation as well as reduction or no change $[33,34]$ on bone resorption. The changes observed in this study, therefore, are not contradictory to other studies and slight differences observed may be attributed to sample size, isoflavone dosing, period of intervention and dissimilarity of the studied groups.

\section{Conclusion}

In conclusion it seems soy protein can be effective in protecting bone mass through curbing bone resorption specially in high risk groups as was demonstrated in our osteopenic subjects but not enhance bone formation. Different studies have reported intake of 70-90 milligrams of isoflavones per day to be effective. Soy protein in our study provided $98 \mathrm{mg}$ of isoflavones which is in accordance with other studies $[35,36]$. Some have reported lesser amounts can be effective in longer periods of time [37]. Soy protein consumption, thus, is a valuable plant estro-

Table 2: Subjects mean food intake in 3 stages of the study $(n=15)$.

\begin{tabular}{|c|c|c|c|c|}
\hline Variables & at the start & 6 weeks & 12 weeks & P value ${ }^{* *}$ \\
\hline Energy (kcal) & $1933.4 \pm 302.5^{*}$ & $2033.2 \pm 420.3$ & $1902.8 \pm 308.6$ & NS *** $^{*}$ \\
\hline Protein (g) & $74.6 \pm 12.3$ & $71.9 \pm 17.4$ & $74.8 \pm 10.2$ & NS \\
\hline Calcium (mg) & $999.3 \pm 460.2$ & $966.8 \pm 443.7$ & $1014 \pm 436$ & NS \\
\hline Phosphore (mg) & $873.2 \pm 228.9$ & $853.1 \pm 273.9$ & $866.4 \pm 200.6$ & NS \\
\hline
\end{tabular}

\footnotetext{
* Mean \pm SD

** significant level was set at below 5 percent $(P<0.05)$.

*** To analyze changes in 3 stages, repeated measurement analysis was utilized.
} 
Table 3: Bone metabolism biomarkers in 3 stages of the study $(n=15)$.

\begin{tabular}{|c|c|c|c|c|}
\hline Variables* & At the start & 6 weeks & 12 weeks & $\mathbf{P}_{\text {value }}{ }^{\dagger}$ \\
\hline TALP (IU/I) & $237.5 \pm 85.4^{* *}$ & $300.4 \pm 294.1$ & $281.3 \pm 80.5$ & $<0.05$ \\
\hline OC (ng/ml) & $1 \mathrm{l} .4 \pm 4.8$ & $12.7 \pm 5.7$ & $11.5 \pm 4.8$ & NSt† \\
\hline IGFBP3 (ng/ml) & $3304.6 \pm 728.6$ & $3221.6 \pm 534.4$ & $3103.9 \pm 639.8$ & NS \\
\hline DPD (nmol/mmol) & $7 \pm 1.2$ & $5.9 \pm 1.1$ & $5.1 \pm 2.1$ & $<0.05$ \\
\hline C-TX (ng/ml) & $0.79 \pm 0.49$ & $0.8 \pm 0.4$ & $0.8 \pm 0.3$ & NS \\
\hline ITCP $(\mu \mathrm{g} / \mathrm{I})$ & $4.6 \pm 0.9$ & $4.3 \pm 0.9$ & $5.9 \pm 1.1$ & NS \\
\hline
\end{tabular}

* TALP: Total alkaline phosphatase (IU/l); OC: Osteocalcin (ng/ml); IGFBP3: Insulin like growth factor binding protein 3 (ng/ml); DPD:

Deoxypyridinoline (nmol/mmol); C-TX: C-Telopeptides ( $\mathrm{ng} / \mathrm{ml})$; ITCP: Carboxy terminal telopeptides of type I collagen $(\mu \mathrm{g} / \mathrm{l})$

** Mean \pm SD

† To analyze changes in 3 stages, repeated measurement analysis was utilized.

t† significant level was set at below 5 percent $(P<0.05)$.

gen which can be recommended for osteoporosis prevention.

\section{List of abbreviations}

BAP: Bone-specific Alkaline Phosphatase

BMI: Body Mass Index

CTX: Collagen type I cross-Linked C-telopeptide

Dpd: Deoxypyridinoline

ELISA: Enzyme Linked Immunosorbent assay

IU/l: International Unit/liter

IGFBP3: Insulin Like Growth Factor-Binding Protein 3

IRMA: Immuno Radiometric Assay

ITCP: Serum Carboxyterminal telopeptide of type I collagen

Kcal: Kilocalorie

$\mathrm{Kg} / \mathrm{m}^{2}$ : kilogram/meter ${ }^{2}$

Ks: Kolmogrof-smirnof

mg: miligram

n mol/m mol: nano mol/mili mol

ng/ml: nanogram/mililiter

Oc: Osteocalcin

RIA: Radioimmunoassay

TALP: Total Alkaline Phosphatase $\mu \mathrm{g} / \mathrm{L}:$ microgram/Liter

\section{Competing interests}

The author(s) declare that they have no competing interests.

\section{Authors' contributions}

This research is the title of AHR's thesis. She has designed the frame of research and performed the subjects' selection, intervention, follow up of subjects, data gathering and data analysis and finally writing and editing of this manuscript was carried out by her.

FT: Advisor of thesis.

AHN assisted with subjects collection and data analysis. He also contributed in performing the laboratory tests.

BA Measured the soy phytoestrogens.

BL and MK: conceived of the study and participated in its design.

\section{Acknowledgements}

Grant of this project was supplied by Endocrinology \& Metabolism

Research Center of Tehran Medical University.

\section{References}

I. Barrett CE: Epidemiology and the menopause:A global overview. Int J Fertil 1993, 38:6-14.

2. Dempster DW, Lindsay R: Pathogenesis of osteoporosis. Lancet 1996, 341:797-801.

3. Position statement of the north american menopause society: Management of postmenopausal osteoporosis. Menopause 2002, 9(2):84- 101 .

4. Scharbo DM: Hormone replacement therapy. Nurse Pract 1996, 21:1-13.

5. Groeneveld FP, Bareman FP, Barensen r, et al.: Determinants of first prescription of hormone replacement therapy. A follow up study among 1689 women aged 45-60 years. Maturitas 1994, 20:8I-89.

6. Lignieres DB: Hormone replacement therapy: clinical benefits and side-effects. Maturitas 1996:31-36. 
7. Glazier MG, Bowman MA: A review of the evidence for the use of phytoestrogens as a replacement for traditional estrogen replacement therapy. Arch Intern Med 2001, 161:1161-1172.

8. Ross PD, Norimatsu H, Davis JW, Yano K, Wasnich RD, et al.: A comparison of hip frcture incidence amonge native Japanese, Japanese Americans, and American Caucasians. Am J Epidemiol | 99|, | 33:80|-809.

9. Adlercreutz H, Mazur W: Phytoestrogens and Western diseases. Ann Med 1997, 29:95-I20.

10. Simoon F: Food in china: a cultural and historical inquiry. Boca Raton, FL: CRC press Inc; 1991.

II. Kurzer MS, Xu X: Dietary phytoestrogens. Ann Rev Nutr 1997, 17:353-38I.

12. Coward L, Barnes NC, Setchell EDR, Barnes S: Genistein, daidzein and their $\beta$-glucoside conjugates: antitumor isoflavones in soybean foods from American diets and Asian diets. J Agri Food Chem 1993, 41:1961-1967.

13. Messina MJ: Legumes and soybeans: Overview of their nutritional profiles and health effects. Am J Clin Nutr 1999:439-450.

14. Wangen KE, Duncan AM, Merz-Demlow BE, et al.: Effects of soy isoflavones on markers of bone turnover in premenopausal and postmenopausal women. J Clin Endocrinol Metab 2000, 85:3043-3048.

15. Kuiper GG, Carisson B, Grandien K, et al.: Comparison of the ligand binding specifity and transcript tissue distribution of estrogen receptors alpha and beta. Endocrinology 1997, 1 38:863-870.

16. National Nutrition Institute: National food consumption survey report. Tehran, Iran. 1995.

17. Watts NB: Clinical utility of biochemical markers of bone remodeling. Clin Chem 1999, 45(8 Pt 2):।359-1368.

18. Arjmandi BH, Alekel L, Hollis BW, Amin D, et al.: Dietary soybean protein prevents bone loss in an ovariectomized rat model of osteoporosis. J Nut 1996, 126:161-167.

19. Arjmandi BH, Getlinger MJ, Goyal NV, Alekel I, Hasler CM, et al.: Role of soy protein with normal or reduced isoflaonecontent in reversing bone loss induced by ovarian hormone deficiency in rats. Am J Clin Nutr 1998:1358-1363.

20. Arjmandi BH, Birnbaum R, Goyal NV, Getlinger MJ, et al.: Bone sparing effect of soy protein in ovarian hormone-deficient rats is related to its isoflavone content. Am J Clin Nutr 1998:1364-1368.

21. Chang YC, Nair MG: Metabolism of daidzein and genistein by intestinal bacteria. J Nutr Proc 1995, 58: | 892-1896.

22. Xu X, Harris KS, Wang HJ, Murphy PA, Hendrich S: Bioavailability of soybean isoflavones depends upon gut microflora in women. J Nutr 1995, 1 25:2307-23 I5.

23. Sathyamoorthy N, Wang TTY: Differential effects of dietary phyto-oestrogens daidzein and equol on human breast cancer MCF-7 cells. Eur J Cancer 1997, 33:2384-2389.

24. Setchell KDR, Adlercreutz $\mathrm{H}$ : Mammalian lignans and phytoestrogens: recent studies on their formation, metabolism, and biological role in health and disease. In Role of the gut flora in toxicity and cancer Edited by: Rowland IR. Academic Press. London, United Kingdom; 1988:315-345.

25. Register TC, Jayo MJ, Anthony MS: Soy phytoestrogens do not prevent bone loss in postmenopausal monkeys. J Clin Endocrinol Metab 2003, 88:4362-4370.

26. Clarkson TB, Anthony MS, Morgan TM: Inhibition of postmenopausal atherosclerosis progression: a comparison of the effects of conjugated equine estrogens and soy phytoestrogens. J Clin Endocrinol Metab 200I, 86(I):4I-47.

27. Setchell KD, Brown NM, Lydeking-Olsen E: The clinical importance of the metabolite equol-a clue to the effectiveness of soy and its isoflavones. I Nutr 2002, I 32( ( 2):3577-3584.

28. Arjmandi Bh, Khalil DA, Smith BJ, et al.: soy protein has a greater effect on bone in postmenopausalwomen not on hormon replacement therapy as evidenced by reducing bone resorption and urinary calcium excretion. J Clin Endocrinol Metab 2003, 88:1048-1054.

29. Yamori Y, Moriguchi EH, Teramoto T, Miura A, et al.: Soybean isoflavones reduce postmenopausal bone resorption in female Japanese immigrants in Brazil:A ten week study. J Am Coll Nutr 2002, $21(6): 560-563$.

30. Picherit C, Pelissero CB, Chanteranne B, Lebecque P, et al:: Soybean isofavones dose-dependently reduce bone turnover but do not reverse established osteopenia in adult ovariectomized rats. J Nutr 200I, I 3 I:723-728.

31. Uesugi T, Fukui Y, Yamori Y: Beneficial effects of soybean isoflavone supplementation on bone metabolism and serum lipids in postmenopausal Japanese women: a four week study. J Am Coll Nutr 2002, 21:97-102.

32. Fanti P, Monier-Faugere MC, Geng Z, et al:: The phytoestrogen genistein reduces bone loss in short term ovariectomized rats. Osteoporosis Int 1998, 8:274-28I.

33. Agnusdei D, Crepaldi G, Isaia $G$, et al.: A double blind, placibo controlled trial of ipriflavone for prevention of postmenopausal spinal bone loss. Calcif Tissue Int 1997, 61:142-147.

34. Gennari C, Agnusdei D, Crepaldi G, et al.: Effect of ipriflavone-a synthetic derivative of natural isoflavones-on bonemass loss in the early years after menopause. Menopause 1998, 5:9-15.

35. Potter SM, Baum JA, Teng H, Stillman RJ, et al.: Soy protein and isoflavone: their effects on blood lipids and bone density in postmenopausal women. Am / Clin Nutr 1998, 68(suppl 6): I 375- I 379.

36. Alekel DL, Germain AS, Peterson CT, Hanson KB, et al.: Isoflavonerich soy protein isolate attenuates bone loss in the lumbar spine of perimenopusal women. Am J Clin Nutr 2000, 72:844-852.

37. Barnes S: Phytoestrogens and osteoporosis - What is a safe dose? $\mathrm{Br}$ J Nutr 2003, 39: 10I-108.
Publish with Bio Med Central and every scientist can read your work free of charge

"BioMed Central will be the most significant development for disseminating the results of biomedical research in our lifetime. "

Sir Paul Nurse, Cancer Research UK

Your research papers will be:

- available free of charge to the entire biomedical community

- peer reviewed and published immediately upon acceptance

- cited in PubMed and archived on PubMed Central

- yours - you keep the copyright

Submit your manuscript here:

http://www.biomedcentral.com/info/publishing_adv.asp 